\title{
EAD HISTÓRICO, COMPETÊNCIAS E HABILIDADES DA TUTORIA NOS CURSOS DE FONOAUDIOLOGIA
}

\author{
Patrícia Arruda de Souza Alcarás, Maria Eliza Nigro Jorge \\ Universidade do Oeste Paulista - UNOESTE. Curso de Fonoaudiologia, Presidente Prudente - SP. E-mail: \\ parruda@unoeste.br
}

\section{RESUMO}

Tendo em vista que o ensino à distância está cada vez mais presente no processo de ensinoaprendizagem, o presente estudo visa apresentar as competências e habilidades que o professor tutor deve ter ao ministrar cursos à distância na área da Fonoaudiologia. Trata-se de um estudo bibliográfico o qual enfatizou a história do Curso da Fonoaudiologia e sua recente inserção na modalidade de ensino à distância, além de relatar as competências que o professor tutor deve ter no desempenho das suas práticas docentes. Com isso, é possível observar mediante aos estudos apresentados que as competências do tutor, as práticas do profissional fonoaudiólogo vão ao encontro das práticas pedagógicas propostas no ensino à distância, pois além de ser capaz de lançar desafios para capacitar o aluno com atitudes crítico-reflexivos, desenvolve ações centralizadas no aprender, contribui nas interações entre os pares e favorece as práticas de pesquisa.

Palavras-chave: Fonoaudiologia; EaD; Tutoria; Educação; Aprendizagem.

\section{EAD: HISTORY, SKILLS AND ABILITIES IN THE TUTORING COURSES SPEECH AND HEARING THERAPY}

\begin{abstract}
Given that distance education is increasingly present in the teaching-learning process, this study aims to present the skills and abilities that the tutor should have to teach distance courses in the area of Speech and Hearing Therapy. This is a bibliographic study which emphasize the history of the College of Speech and Hearing Therapy and its recent inclusion in the form of distance learning, in addition to reporting the competencies that the tutor must have in the performance of their teaching practices. This makes regarding the competence of the tutor, the practices of professional speech therapists will meet the proposed pedagogical practices in distance education, because in addition to being able to throw challenges to empower students with critical-reflexive attitudes, develops centered on learning actions, contributes in interactions among peers and encourages research practices.
\end{abstract}

Keywords: Speech and hearing therapy; Distance learing; Tutoring; Education; Learning.

\section{INTRODUÇÃO}

A modalidade de Educação à Distância está cada vez mais em destaque no processo de ensino-aprendizagem, visto que há possibilidades do aluno construir o seu conhecimento mediante a sua realidade. 
Faria e Salvadori (2010), relataram em seus estudos que a Educação à Distância (EaD) se destaca pelo fato dessa modalidade de ensino superar barreiras do "espaço e tempo", o qual o aluno tem autonomia em realizar as atividades programadas e importantes para a construção do seu conhecimento.

Por utilizar diferentes recursos de informação, com apoio de materiais didáticos organizados em diversos meios de comunicação, a EaD é considerada uma forma de ensino que possibilita a auto-aprendizagem, segundo a Leis de Diretrizes e Bases - LBD, uma vez que o aluno é o principal autor da sua aprendizagem (COSTA; FARIA, 2008).

Nessa modalidade de ensino, a postura do educador deve ser pautada no levantamento constante do pensamento crítico, considerando a inclusão de novas mediatizações nesse processo de educação (SALDANHA, 2008).

Kenski (2005) relatou que há infinitas possibilidades de interação entre aluno e professor, o que proporcionará maior dinâmica nas aulas ministradas à distância, além de criar novos vínculos entre os participantes do curso ministrado. Para tanto, necessita-se que o professor tenha formação plena para atuar à distância, visto que segurança em administrar as diferentes formações entre os participantes, favorecendo no processo de ensino-aprendizagem é fundamental para a construção do conhecimento.

Tecchio et al. (2009) relataram que o tutor é o principal responsável pelo sucesso do curso à distância, pois além dele apresentar domínio sobre o conteúdo ministrado, deve estimular o aluno à buscar respostas para a construção do seu conhecimento.

Para tanto, as atitudes que o tutor deve ter estão relacionadas com as competências comportamentais, o qual o tutor deve desempenhar papeis referentes à organização e planejamento, ser pró-ativo, ser auto-motivador, ter capacidade de análise e síntese, ter empatia com os demais membros, apresentar equilíbrio emocional, ter flexibilidade, ser assíduo, ser comprometido com o curso, ter espírito de liderança e ser criativo (TECCHIO et al, 2009).

Tendo em vista que o ensino à distância está cada vez mais presente no processo de ensino-aprendizagem, o presente estudo visa apresentar as competências e habilidades que o professor tutor deve ter ao ministrar cursos à distância na área da Fonoaudiologia.

Trata-se de um estudo de metodologia bibliográfica, o qual enfatiza a prática pedagógica do Curso da Fonoaudiologia na modalidade de ensino à distância, além de relatar as competências que o professor tutor deve ter no desempenho das suas práticas docentes. 


\section{EaD como prática pedagógica na área da Fonoaudiologia}

Segundo Trenche, Barzaghi e Pupo (2008), as diretrizes curriculares de diversos cursos de graduação vêm se modificando, cujo intuito é conectar o perfil do profissional com a área de atuação. Com propostas baseadas nas diretrizes do Sistema Único de Saúde - SUS, a formação do profissional da saúde vem focalizando a necessidade de construir um modelo pedagógico que "equilibrem excelência técnica e relevância social".

O curso de Fonoaudiologia foi criado em uma perspectiva de orientação profissional centrada na vocação clínico-terapêutico, e mais tarde foram atribuídas outras possibilidades de atuação, como pesquisa e assessoria. Baseada na orientação curricular proposta pelo Ministério da Educação, as disciplinas foram organizadas em três núcleos de formação, sendo elas o fundamental, clínico-terapêutico e assessoria. Com as mudanças nos cursos de ensino superior promulgadas pelas Leis de Diretrizes e Bases (LBD/1996) e resolução das diretrizes curriculares dos cursos de Fonoaudiologia, foram definidos o perfil, as competências e habilidades do profissional, bem como os campos de saberes da sua formação (TRENCHE; BARZAGHI; PUPO, 2008).

No ensino à distância, a mediação das práticas-pedagógicas voltadas ao processo de ensino-aprendizagem ocorrem por intermédio das novas tecnologias de informação e comunicação (TICs).

Blasca et al (2010) citaram em seus estudos que a educação à distância está em uma fase promissora pois além de agregar conhecimento pela relação entre as pessoas, reduz as dificuldades em relação ao espaço físico e o custo, e otimiza o tempo.

Para que isso ocorra, é necessário um plano pedagógico que contemple essa nova modalidade de ensino. Nessa perspectiva, os cursos de graduação e pós-graduação em Fonoaudiologia têm elaborado materiais educacionais que "auxiliem no exercício docente". Uma ferramenta bastante utilizada pela Fonoaudiologia com intuito de atingir os alunos e professores de forma efetiva sem defasar a qualidade do ensino é a teleducação (BLASCA et al, 2010).

Wen (2008) comentou em seu estudo que a teleducação interativa surgiu com intuito de promover melhorias na qualificação de professores da área da saúde em atenção básica, favorecendo assim melhor qualidade de serviço à população. Segundo o autor, é designado o termo "teleducação e rede de aprendizagem colaborativa" ao uso de novas tecnologias na construção do conhecimento, o que irá proporcionar facilidades ao acesso de materiais educacionais sem perder a qualidade, além de "permitir acesso a centro de referências ou a estruturação de novas sistemáticas educacionais". 
Blasca e Bevilacqua (2006) referiram que a elaboração de materiais didáticos para uso na EaD estão voltados à conteúdos para o ensino, o qual as informações ali contidas são importantes "pelo fato de serem programadas para a mediação pedagógica, que é o tratamento de conteúdo e de formas de expressão dos diferentes temas, a fim de tornar possível o ato educativo mais participativo, com maior criatividade e expressividade".

Na Fonoaudiologia, há uma preocupação em proporcionar um ensino de qualidade e boa formação profissional, visto que a atuação é voltada ao atendimento ao paciente, o que influenciará de forma favorável no diagnóstico e prognóstico do paciente.

Reis e Silva (2011) realizaram um estudo visando analisar e discutir como o desenvolvimento nas ciências da educação tem contrastado com abordagens mais antigas, as quais ainda são muito utilizadas na prática docente. Com esse propósito, os autores concluíram que a EaD deve adotar soluções que:

flexibilize o acesso aos recursos de aprendizagem, promovam interação e cooperação, permitam a reutilização e interoperabilidade de conteúdos educativos, implementem estratégias pedagógicas adequadas a uma melhor aprendizagem, facilitem a procura de recursos educativos e disponibilizem cursos adaptados às necessidades do aluno.

Prado et al (2008) comentaram em seu estudo que a utilização de ferramentas computacionais no processo de ensino e assistência tem sido bastante utilizadas por profissionais da área da saúde, cujos modelos de ensino tem sido pautados na utilização de um "Cybertutor" e confecção de materiais interativos online.

Segundo o Conselho Federal de Fonoaudiologia (CFFa. Art. $1^{\circ}$, 2013) a Telessaúde em Fonoaudiologia é definida pelo exercício da profissão por intermédio das novas tecnologias, as quais o profissional poderá "prestar serviços em saúde como teleconsultoria, segunda opinião formativa, teleconsulta, telediagnóstico, telemonitoramento e teleducação, visando o aumento da qualidade, equidade e da eficiência dos serviços e da educação profissional".

Ainda, segundo o CFFa (2013) a prestação de serviços por intermédio da telessaúde pode ser dividida em teleconsultoria, segunda opinião formativa, teleconsulta, telediagnóstico, telemonitoramento e teleducação.

No que diz respeito à teleducação, a atuação está voltada em ações de ensinoaprendizagem à distância por intermédio das teleconferências, apresentação de conteúdos em ambiente virtual de aprendizagem e teleconsultoria educacional (CFFa. Art 6², 2013).

Com objetivo de analisar e discutir a aprendizagem em uma disciplina ofertada à distância, na área da saúde, Signorini et al (2012) comentaram em seu estudo que para "despertar a 
consciência crítica e analítica do homem" é preciso adequar a metodologia de ensino, cujos conteúdos apresentados devem diferir aos conteúdos apresentados no ensino presencial, visto que não há contato direto entre aluno e professor. Para tanto, os autores citaram um estudo no qual dizia que o planejamento de uma disciplina ofertada à distância deve ser bem estruturada quanto a definição dos objetivos e resultados, material didático que contemple a temática e estabelecer um roteiro para a disciplina.

\section{Competências e habilidades da tutoria na área da Fonoaudiologia}

Soek e Gomes (2008) comentaram em seu estudo que o ensino à distância requer de profissionais com formação plena para atuar nessa nova modalidade de ensino. Para tanto, o professor tutor deve estar centrado no "fazer aprender, na criação, na gestão e na regulação de situações de aprendizagem".

Tendo em vista que o processo de aprendizagem vem da construção do conhecimento do aluno, o professor tutor deve assumir o papel de provedor desse processo educativo, o qual irá "promover a participação, a comunicação, a interação e o confronto de ideias" (SOEK; GOMES, 2008).

Sendo assim, o tutor que atua na modalidade de ensino à distância, além de apresentar perfil para atuar nessa modalidade, deve administrar, orientar, incentivar e motivar o aluno, visando uma atuação mediadora do conhecimento.

Marchi et al (2011) relataram que o tutor, à priori, deve "orientar o aluno facilitando sua vida de estudante online", a fim de motivá-lo e envolvendo-o nas atividades proporcionadas pelos curso, favorecendo assim a construção de sua formação.

Com isso, o tutor precisa ter responsabilidade, capacidade e competência para atuar na EaD:

Mercado (2008, p. 98) define o tutor como responsável pela incessante comunicação que desencadeia o processo de ensino-aprendizagem; é o parceiro constante das esferas envolvidas no processo, ou seja, do professor e, em especial, do aluno, devendo interagir com os dois grupos, tanto com ações motivacionais quanto na resolução de problemas técnicos (apud MARCHI et al, 2011).

Sendo assim, o tutor deve ter capacidade para "interagir com os conteúdos e material didático disponibilizado e dinamizado durante o curso", orientar o aluno, intervir quando necessário, estar presente no ambiente virtual e incentivar a autonomia do aluno. (BELLONI, 2003, P. 81 apud MARCHI et al, 2011). 
No campo de atuação da Fonoaudiologia a tutoria foi desenvolvida com o objetivo:

lançar desafios para desenvolver a capacidade do aluno de articular estudos desenvolvidos nas várias disciplinas com as questões trabalhadas pelos seminários; facilitar o processo educacional; promover ações que resultassem em atitudes crítico-reflexivas; desenvolver atividades focalizadas no aprender, e não no ensinar; assegurar a participação de todos os estudantes, incentivando a iniciativa de contribuição à discussão grupal; auxiliar a auto-avaliação discente e identificação de necessidades para melhor aproveitamento acadêmico; estimular processos de integração e cooperação grupal; iniciar os estudantes em métodos de pesquisa científica (TRENCHE; BARZAGHI; PUPO, 2008).

Para Martins (2003), é papel do tutor acompanhar o aprendizado do aluno. Para tanto, o tutor precisa apresentar maturidade emocional, ter espírito de liderança, ter bom conhecimento cultural, ter empatia, ser cordial e saber ouvir.

Sendo assim, um dos maiores desafios do professor que atua na EaD é construir um ambiente de aprendizagem colaborativo, a fim de que o aluno desenvolva a autonomia sobre o seu próprio aprendizado, e nessa perspectiva, o tutor atuação do tutor é fundamental, visto que ele irá mediar o processo de ensino-aprendizagem do aluno (MARTINS, 2003).

\section{CONSIDERAÇÕES FINAIS}

O presente estudo visou mostrar um breve histórico da Fonoaudiologia, bem como as competências e habilidades que o professor tutor deve ter ao ministrar cursos à distância na área da Fonoaudiologia.

Mediante ao que foi apresentado, é possível verificar que as práticas do profissional fonoaudiólogo vão ao encontro das práticas pedagógicas propostas no ensino à distância, pois além de ser capaz de lançar desafios para capacitar o aluno com atitudes crítico-reflexivos, desenvolve ações centralizadas no aprender, contribuindo nas interações entre os pares e favorecendo as práticas de pesquisa.

Entretanto, não foi possível fazer maiores inferências sobre a temática visto que não há muitos estudos na área da Fonoaudiologia sobre o tema abordado. Para tanto, acredita-se que o presente estudo poderá favorecer em novos estudos sobre a Fonoaudiologia na Educação à Distância, uma vez que essa modalidade de ensino está cada mais presente no processo de aprendizagem acadêmica. 


\section{REFERÊNCIAS}

1. BLASCA, W.Q.; BEVILACQUA, M.C. A multimídia como uma nova proposta de ensino da audiologia, Salusvita, vol. 25, n. 3, p. 389-402, 2006. Disponível em:

http://www.usc.br/biblioteca/salusvita/salusvita_v25_n3_2006_art_09.pdf Acesso em: 27 de mai, 2014.

2. BLASCA, W.Q; MAXIMINO, L.P.; GALDINO, D.G.; CAMPOS, K de; PICOLINI, M. M. Novas tecnologias educacionais no ensino da audiologia. Rev Cefac, vol. 12, n. 6, p 1017-1024. 2010. Disponível em: http://www.scielo.br/pdf/rcefac/v12n6/133-09.pdf Acesso em: 20 de mai, 2014.

3. COSTA, K. S.; FARIA, G.G. EAD - sua origem histórica, evolução e atualidade brasileira face ao paradigma da educação presencial. Relatório de Pesquisa: Associação Brasileira de Ensino à Distância, 2008. Disponível em: http://www.abed.org.br/congresso2008/tc/552008104927am.pdf Acesso em: 15 de mai, 2014.

4. CONSELHO FEDERAL DE FONOAUDIOLOGIA. Resolução do Conselho Federal de Fonoaudiologia - CFFa N427 de 01-03-2013. Disponível em:

http://www.normaslegais.com.br/legislacao/resolucao-cffa-427-2013.htm Acesso em: 29 de mai, 2014.

5. FARIA, A. A.; SALVADORI, A. A educação a distância e seu movimento histórico no Brasil. Rev das Faculdades Santa Cruz, v. 8, n. 1, jan/jun, 2010. Disponível em:

http://santacruz.br/v4/download/revista-academica/14/08-educacao-a-distancia-e-seumovimento-historico-no-brasil.pdf Acesso em: 15 de mai, 2014.

6. KENSKI, V. M. Das salas de aula aos ambientes virtuais de aprendizagem. Relatório de Pesquisa. USP: 2005, 80 p. Disponível em: www.abed.org.br/congresso2005/por/pdf/030tcc5.pdf Acesso em: 19 de mai, 2014.

7. MARCHI, A. C. B. de; STREIT, I. R.; ARAÚJO, D. D.; DIEDRICH, M. S. A prática da tutoria online por meio de competências: estudo de caso de uma metodologia aplicada ao curso de Formação de Tutores. Novas Tecnologias na Educação, vol. 9, n. 1, 2011. Disponível em: file://C:/Users/alcaras/Downloads/21894-80533-1-SM.pdf Acesso em: 29 de mai, 2014.

8. MARTINS, O. B. Teoria e prática tutorial em educação a distância. Rev Educar, n. 21, p. 15371, 2003. Disponível em: file://C:/Users/alcaras/Downloads/2128-4107-1-PB.pdf Acesso em: 29 de mai, 2014.

9. PRADO, L. M. do; ARAÚJO, E. S.; SANTOS, M. J. D. do; GIGLIOTTI, M. P.; SATHLER, R.; FERNANDES, T. M. F.; et al. Proposta de ensino à distância na prática interdisciplinar fonoaudiológica e odontológica. $18^{\circ}$ Congresso Brasileiro de Fonoaudiologia. Campos do Jordão, SP, 2008. Disponível em: http://www.sbfa.org.br/portal/anais2008/resumos/R0228-1.pdf Acesso em: 29 de mai, 2014.

10. REIS, P.; SILVA, F. Ensino à Distância: desafios pedagógicos. Rev Cibertextualidade, anual 4, 2011. Disponível em: http://bdigital.ufp.pt/bitstream/10284/2328/3/cibertxt_4_reis_silva_pt.pdf Acesso em: 27 de mai, 2014. 
11. SALDANHA, L. C. D. Concepções e desafios na educação à distância. Relatório de Pesquisa. UNICOC: 2008, 10 p. Disponível em: www.abed.org.br/congresso2008/tc/511200810841PM.pdf Acesso em: 19 de mai, 2014.

12. SIGNORINI, A. V.; AYRES, A.; SEIMETZ, B. M.; FLORES, L. S.; OLCHIK, M. R. Aprendizagem EAD em saúde: análise de uma vivência. Salão de Ensino: Universidade Federal do Rio Grande do Sul, Porto Alegre, RS, 2012. http://hdl.handle.net/10183/71160 Acesso em: 29 de mai, 2014.

13. SOEK, A. M.; GOMES, D. L. As relações de ensino/aprendizagem na Educação à Distância e o trabalho do tutor como mediador do conhecimento. Revista Intersaberes, ano 3, n. 6, jul-dez, 2008. Disponível em:

file:///C:/Users/alcaras/Downloads/As\%20relac_oes\%20de\%20ensino_aprendizagem\%20na\%20E AD\%20eo\%20o\%20tutor\%20como\%20mediador\%20(3).pdf Acesso em: 29 de mai, 2014.

14. TECCHIO, E. L.; NUNES, T. S.; MORETTO, S. M.; DALMAU, M. B. L.; MELO, P. A.

Competências fundamentais ao tutor de ensino à distância. Revista Digital da CVA - Ricesu, v. 6, n. 21, out, 2009. Disponível em:

http://pead.ucpel.tche.br/revistas/index.php/colabora/article/viewFile/122/107 Acesso em: 19 de mai, 2014.

15. TRENCHE, M. C. B.; BARZAGHI, L.; PUPO, A. C. Mudança curricular: construção de um novo projeto pedagógico de formação na área da Fonoaudiologia. Comunicação Saúde Educação, vol. 12, n. 27, p. 697-711, out/dez, 2008. Disponível em:

http://www.scielo.br/pdf/icse/v12n27/a02v1227.pdf Acesso em: 29 de mai, 2014.

16. WEN, C. L. Telemedicina e Telessaúde - um panorama no Brasil. Informática Pública, ano 10, n. 2, p. 07-15, 2008. Disponível em:

http://www.ip.pbh.gov.br/ANO10_N2_PDF/telemedicina_telesaude.pdf Acesso em: 27 de mai, 2014. 